\title{
Deconstructing MACRA: the switch from volume- to value-based payment
}

\author{
Interviewer Linda Bosserman, MD, City of Hope, Rancho Cucamonga, California Interviewee Robin Zon, MD, \\ Michiana Hematology Oncology, South Bend, Indiana \\ Based on a presentation by Dr Zon with Phil Stella, MD, and Blase Polite, MD, at the MACRA Town Hall during the ASCO 2016 annual \\ meeting. The images are reproduced with the permission of ASCO and the presenters.
}

DR BOSSERMAN [LB] I'm an editor at THE Journal of Community and Supportive Oncology. I'm also Assistant Clinical Professor at City of Hope, where I specialize in value-based care and breast cancer. I'm on the board of directors of the American Society of Clinical Oncology [ASCO] and a member of its Pathway and Physician Payment Reform taskforces and liaison to the Clinical Practice Committee. It's

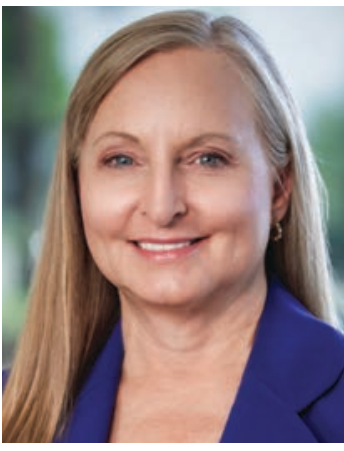
my pleasure to interview my esteemed colleague, Dr Robin Zon, who is going to talk to us about the upcoming Medicare Access and CHIP Reauthorization Act of 2015 [MACRA] legislation.

DR ZON [RZ] Thank you Linda for asking me to join you. It's my pleasure to talk with you about MACRA. I am a community oncologist. I work in an independent practice in the South Bend, Indiana, area where I am a Vice President and Chair of both the finance and quality committees. In addition, I am an active ASCO volunteer, recently having been the immediate past

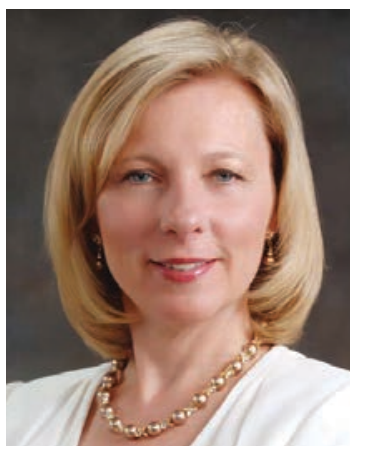
chair of the clinical practice committee and the chair elect of the government relations committee. I've been involved in a number of works for ASCO, including leadership of the
Clinical Pathways task force and co-leadership for the MACRA Town Hall at the ASCO meeting.

LB What is MACRA, and why should we be learning about it and paying attention to it now?

RZ Well, we need to do that primarily because it completely changes the basis for Medicare payment and actually moves payments to performance-based updates. It becomes effective in January 2019, but the reason you want to be aware of MACRA today is that the measurements will be based on your 2017 performance, which is just a few months away. [See sidebar on p. 401.]

Let's start with what the acronym means. MACRA stands for Medicare Access and Chip Reauthorization Act of 2015 [Table 1]. It's actually now going to be referenced by the Centers for Medicare \& Medicaid Services [CMS] as the Quality Payment Program, or QPP. Having said that though, MACRA was bipartisan legislation that was signed into law in April 2015 and it does several things. First, it repeals the sustainable growth rate formula also known as the SGR. Second, it changes the way Medicare will pay clinicians and it actually creates a new framework to reward clinicians for value over volume. There will be two major payment programs under MACRA, one called MIPS [Merit-Based Incentive Payment System] and another called AAPMs [Advanced Alternative Payment Models]. Third, MACRA also streamlines the current quality reporting programs that we are involved with.

\section{Medicare as we know it}

LB Can you review how Medicare pays us now?

RZ Today there are a number of different quality and value reporting programs and they all operate separately. For example, we have the Physician Quality Reporting Program, known as PQRS; the Value-Based Payment Modifier, known as VBM; and the Medicare

Correspondence: Linda Bosserman, MD; Ibosserman@coh.org. Disclosures: The authors report no disclosures and no conflicts of interest. JCSO 2016;14(9):394-401. @2016 Frontline Medical Communications. doi: 10.12788/jcso.0297. 
TABLE 1 MACRA by acronym

\begin{tabular}{|ll} 
Acronym/Term & Stands for \\
Mew & Medicare Access and CHIP Reauthorization Act \\
APM or AAPM & Alternative Payment Model or Advanced APM
\end{tabular}

Notes

Passed, 2015; effective, 2019. Replaces SGR; Places value over volume; Streamlines current quality reporting programs.

One of 2 MACRA payment programs. APM: has one-sided risk. Can help Composite Score but requires participation in MIPS. AAPM: has two- sided risk and qualifies for payment under MACRA.

Composite

Score

CPIA Clinical Practice Improvement Activity

MIPS Merit-Based Incentive Payment System

$\begin{array}{ll}\text { QPP } & \text { Quality Payment Program } \\ \text { QRUR } & \text { Quality and Resource Use Report }\end{array}$

\begin{tabular}{|c|c|c|}
\hline \multicolumn{3}{|c|}{ Pre-MACRA } \\
\hline $\mathrm{ACO}$ & Accountable Care Organization & $\begin{array}{l}\text { A group of providers focusing on co-ordinated high-quality } \\
\text { care for Medicare patients. }\end{array}$ \\
\hline CPT & Current Procedural Terminology & $\begin{array}{l}\text { Set of codes to report medical procedures and services (regis- } \\
\text { tered with the AMA) }\end{array}$ \\
\hline$E \& M$ & Evaluation and Management & Services provided under the AMA's CPT \\
\hline MEIP & $\begin{array}{l}\text { Medicare Electronic Health Record (EHR) } \\
\text { Incentive Program }\end{array}$ & $\begin{array}{l}\text { Commonly referred to as 'meaningful use' or 'MU'. To be } \\
\text { called Advancing Care Information going forward. }\end{array}$ \\
\hline NPI & National Provider Identifier & A unique identification number for providers. \\
\hline OCM & Oncology Care Model & A one-sided risk model for 2016 and 2017 \\
\hline PQRS & Physician Quality Reporting Program & $\begin{array}{l}\text { Current quality and value reporting program. To be called } \\
\text { Quality component going forward. }\end{array}$ \\
\hline $\mathrm{TIN}$ & Tax Identity Number & Needed for obtaining your QRUR \\
\hline VBM & Value-Based Payment Modifier & $\begin{array}{l}\text { A payment under the Physician Fee Schedule based quality } \\
\text { of care compared with cost. To be called Resource Use going } \\
\text { forward. }\end{array}$ \\
\hline
\end{tabular}

Electronic Health Record [EHR] Incentive Program [MEIP], referred to in the past as meaningful use [MU]. Each of these quality programs requires different reporting mechanisms and they each have different measures and are associated with incentives and penalties as well. Currently, we are paid based on a physician fee schedule. Then there are adjustments that occur from PQRS penalty or reward, MU penalty or reward, and VBM penalty or reward. These are all added up, and you get your final payment [Figure 1].

\section{MIPS, composite score, and reimbursements}

LB Can you first tell us how the MIPS part of the new MACRA will change the way we are paid?

RZToday, we have these three separate reporting quality measures that are then turned into payment modifications. Under the MACRA-MIPS model, there's actually going to be a composite score where these three measures will be combined with a fourth measure called Clinical Practice Improvement Activity [CPIA]. This payment model will be starting in January 2019. Instead of getting independent scores for
Made up of 4 components, the current MU, PQRS, and VBM, and the new CPIA. It will modify your overall medical payments up or down, beginning 2019.

Rules for CPIA are expected later in 2016.

One of 2 MACRA payment programs. APM: has one-sided risk. Can help Composite Score but requires participation in MIPS. AAPM: has two- sided risk and qualifies for payment under MACRA.

CMS name for MIPS, APM payment programs

Annual report, available in fall for the previous year, showing performance by quality and cost

A group of providers focusing on co-ordinated high-quality care for Medicare patients. tered with the AMA)

Services provided under the AMA's CPT

Commonly referred to as 'meaningful use' or ' $M U$ '. To be called Advancing Care Information going forward.

A unique identification number for providers.

A one-sided risk model for 2016 and 2017

Quality component going forward. Needed for obtaining your QRUR of care compared with cost. To be called Resource Use going forward.

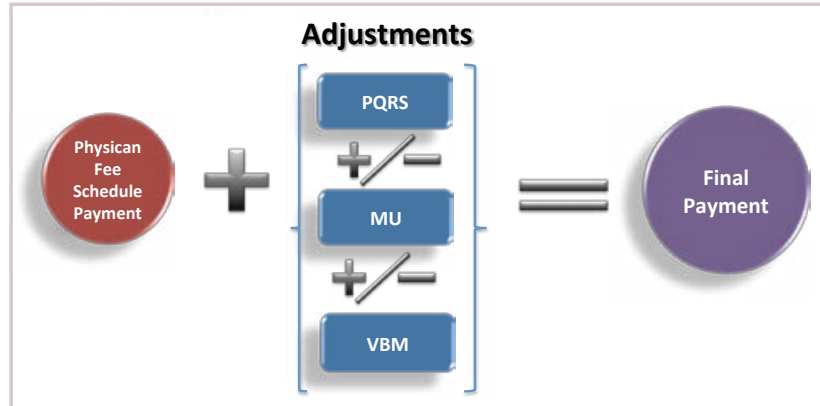

FIGURE 1 How does Medicare pay me now?

PQRS and MU and VBM, you're going to get one composite score against which you will be compared with other providers like you across the nation. That composite score for 2019 will be based on data from your work in 2017.

LB What is the MIPS composite score, and exactly how will it be calculated?

RZ In year one of the MACRA payments, 2019, your pay- 
ments will be based on a MIPS Composite Score made up of each one of the four components - the PQRS, the MU, the VBM, and the CPIA. They will also be given new names and weighted such that Advancing Care Information [currently MU criteria] will have a weighting of 25\%, Quality [currently PQRS criteria] a 50\% weighting, Resource Use [currently VBM measurements] a $10 \%$ weighting, and the CPIA will be weighted 15\% [Figure 2].

The rules for CPIA are yet to be published. They are expected in the final ruling later in 2016. What will happen is that these weightings over the years may change, and CMS has the authority to adjust those weightings in the

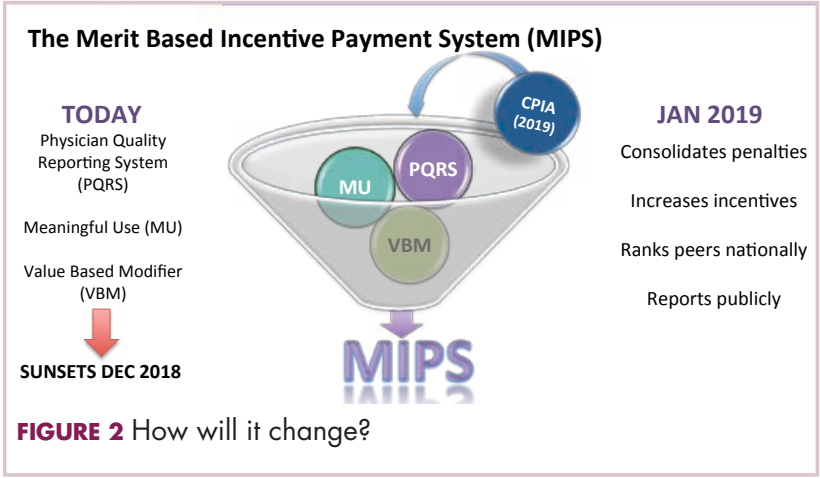

composite scores. Having said that, you will then have a composite score and your score will be compared against the National Mean Composite Score of the Medicare Provider Composite Score. Based on that score, there will be adjustments to your fee schedule payments. Medicare, through the MACRA legislation, has made it very clear that when score calculations are turned into reimbursement readjustments, there will be folks who will be high performers who will be financially rewarded, and there will be low performers whose payments will be penalized.

LB How will that change our overall reimbursement with these adjustments under MIPS?

RZ You'll have your physician fee scheduled payment as you do today, but the adjustment then, as opposed to the independent and separate scores from PQRS, MU, and VBM, will now be part of a single composite score adjustment that will include your resource use to calculate your final payment [Figure 3 and Figure 4].

\section{Timeline for payment adjustments}

LB What is the timeline for this payment adjustment?

RZ For 2016, you are getting a penalty or neutral adjustment for PQRS; a penalty or a neutral adjustment for MU; and a penalty, reward, or neutral adjustment for VBM. Those adjustments are based on your 2014 performance. In 2017 and 2018, you'll be paid the same way but it'll be based on your 2015 and 2016 performances, respectively. By 2019, however, your composite score is going to be
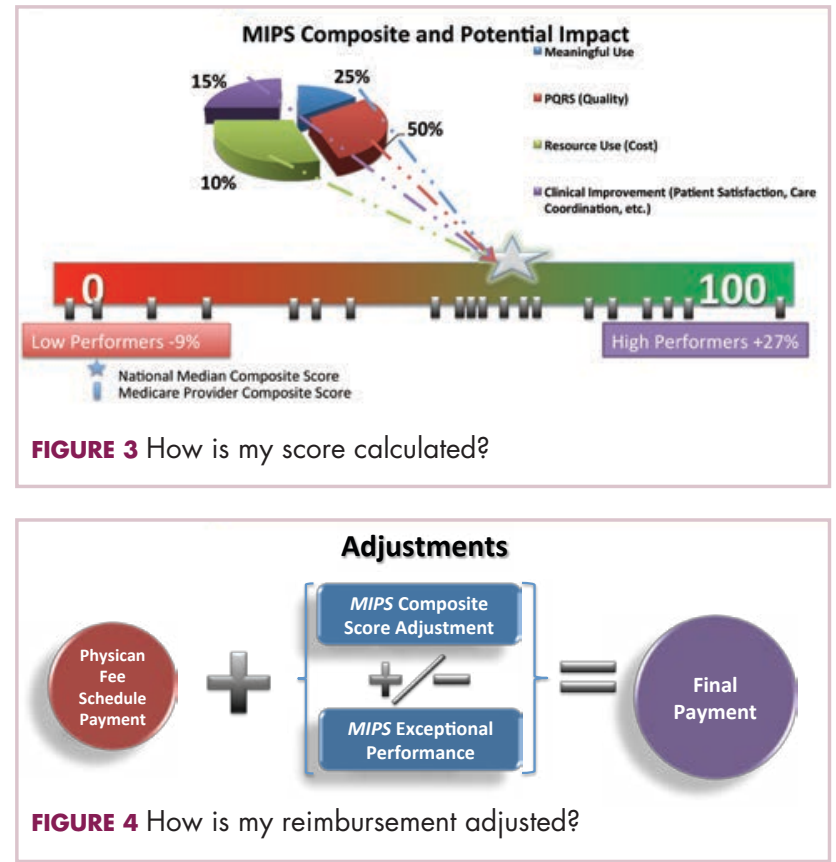

known, based on your 2017 performance, which, as I mentioned, is just a few months away.

For the first year, 2019, of the MACRA-MIPS composite score-based payments, the adjustment can range anywhere from + to $-4 \%$. So low performers will be penalized; high performers will get the upper end of that adjustment. The second year, 2020, will be + to - 5\%, then it'll escalate to + to $-7 \%$, and finally + to $-9 \%$. However, there may be super performers or what they call exceptional performers, and those individuals may actually get an adjustment upward toward 27\% reward [Figure 5].

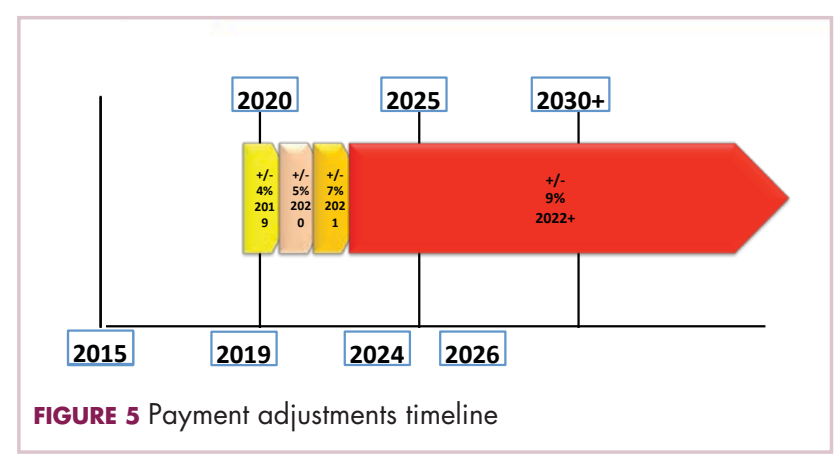

\section{MIPS and the net effect for oncologists}

LB Will these payment changes under the MIPS option of MACRA affect most oncologists?

RZ The answer is yes; it probably will affect most clinicians because MACRA, which is also now being called the Quality Performance Program [QPP], will affect all physician services covered by Medicare Part B. That includes the Evaluation and Management [E\&M] and the Current 
Procedural Terminology [CPT] codes. It does not affect the hospital or the hospice in Medicare Part A, nor does it affect Medicare Advantage in Medicare Part $\mathrm{C}$ or the Part D Medicare prescription drugs [Figure 6].

There are exceptions to participation in MIPS for three groups of individuals. First, the first-time Part B participants for the first year will not be included but once they reach their second year of participation, they will have a composite score and be included in the composite score calculation. The second group will be individual clinicians who provide for a very low volume of patients, which is yet to be defined, but it's likely going to be defined in the rule

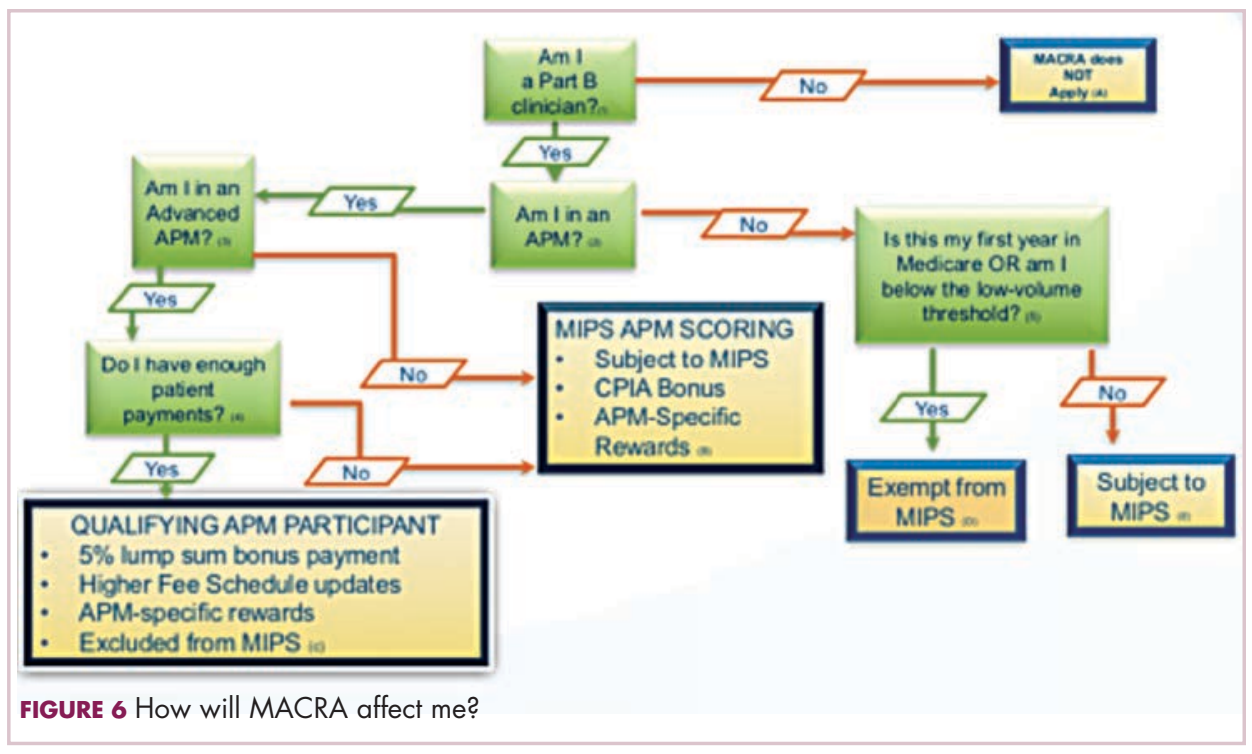
making that will be released later in 2016. Finally, there are going to be participants who are in what we call alternative payments model, although to opt out of MIPS you have to be in a two-sided risk Advanced Alternative Payment Model, or AAPM.

\section{AAPMs and oncologists}

LB Now that you have explained the MIPS payment system under MACRA, can you explain the Advanced Alternative Payment Models and how they might affect oncologists?

RZ Well unfortunately as an oncologist, the current AAPMs don't include us in 2017. An AAPM requires two-sided financial risk. There are currently models that are being used with primary care, such as shared savings programs, something called Next Generation Accountable Care Organization [ACO], a Comprehensive End-Stage Renal Disease Care that has to do with hemodialysis, and Comprehensive Primary Care Plus.

For oncologists, the Oncology Care Model [OCM], which was recently presented by CMS and for which participants have been identified, is only going to be a onesided risk model for 2016 and 2017. Thus it is an APM, but not an AAPM. In 2018, it will become a two-sided risk and then it will be considered an AAPM program eligible for MACRA, but not every oncologist or oncology practice has been chosen to participate.

LB How will providers in AAPMs be paid under the MACRA legislation?

RZ For folks in an APM, for example, if they participate in the new OCM, they will still have to do MIPS in 2016 and 2017 because it is not an Advanced APM until 2018. The benefit of being in the OCM at this point is that it will help their MIPS adjustment be more favorable than if they were not in the OCM.

The third way you can get paid is if you participate in an Advanced APM, although for now, for oncologists, there are no full AAPMs available for 2016 or 2017. When an Advanced APM is available and chosen, you will get specific rewards, will not have to participate in MIPS, and will be eligible to receive a $5 \%$ lump sum bonus. I need to caution you, however, because in the Advanced APM there is a two-sided risk, so although you may get a bonus, with shared two-sided risk, you may also face a reduction.

\section{LB So can you summarize the AAPM payment changes from our current payments?}

RZ Recall that currently, you get the physician fee schedule payments with 3 separate modifiers - MU, PQRS, and VBM. In the only available APM for oncology - the OCM for the first two years - the APM payment will be based on the same physician fee schedule with adjustments from the MIPS Composite Score plus or minus any exceptional performance. By 2018, the OCM will qualify as an AAPM and in that or any other oncology AAPM that is approved, you will be paid on the physician fee schedule payment plus a possible 5\% lump sum Advanced APM bonus for your final payment.

The issue really is, for oncology specifically, that there is no opportunity to participate in Advanced APMs as of today. Thus nearly all practitioners will be subject to MIPS, with a few providers able to participate in the OCMAPMs but they will not be considered advanced so they still will have to participate in MIPS.

Eventually, providers will have available oncology Advanced APMs. Even if you're participating in an Advanced APM, you have to be qualified and the qualification is based on whether or not you have enough revenue payments or patients that are actually being processed 
through that APM to be considered a qualifying participant for Medicare patients.

\section{LB Can you review again, when is all this happening?}

RZ Well as I mentioned earlier, you're going to get your MIPS adjustment starting in 2019 based on 2017. Once two-sided risk oncology Advanced APMs become available, as is the case for the OCMs in 2018, then the 5\% bonus payment may be available. For now, everyone should be preparing for participating in MIPS and optimizing their composite score.

\section{How do oncologists prepare for MACRA?} LB Now that we get how impactful these payment changes with possible significant bonuses and significant penalties are going to be, the question is, what do we do to prepare ourselves starting today?

RZ Well first and foremost, I'm going to describe five steps [Table 2].

STEP 1 is to participate in the three 2016 quality-reporting programs in order to avoid 2018 penalties. These include PQRS, MU, and VBM. For PQRS, although you're no longer being rewarded as that phase has passed, you need to participate because if you don't you will get a negative payment adjustment in 2018. Also participate in the MU, which is the Medicare EHR Incentive Program [MEIP], where you have to successfully attest to avoid negative payment adjustments. Finally, understand and think about choosing wisely and ordering cost effectively to optimize your VBM. The VBM can lead to an upward, neutral, or even a penalty payment adjustment. Many doctors are not aware of the VBM, and I want to make sure I've made it clear that any applicable value-based modifier payment currently will become a component in the MIPS composite score. That component will be separate from the payment

$\begin{aligned} & \text { TABLE } 2 \text { Five steps for preparing for MACRA } \\ & \text { Step }\end{aligned}$ Action
$\begin{array}{ll}\text { Participate in the three } 2016 \text { quality-reporting programs - } \\ \text { PQRS, meaningful use, and VBM - to avoid } 2018 \text { penalties. } \\ \text { RED FLAGMeasurements are based on } 2017 \text { performance. }\end{array}$
$\begin{aligned} & \text { Review your Quality and Resource Use Reports, or QRUR, } \\ & \text { which are available online. }\end{aligned}$
$\begin{aligned} & \text { Focus on performance by reviewing quality benchmarks and } \\ & \text { implementing strategies and workflows to ensure above-aver- } \\ & \text { age performance. }\end{aligned}$
$\begin{aligned} & \text { Ensure data and information accuracy, eg, physician spe- } \\ & \text { cialty and practice address. } \\ & 5\end{aligned}$
$\begin{aligned} & \text { Audit and educate your practice on proper use of the } \\ & \text { International Classification of Diseases, Revision } 10 \text { coding. }\end{aligned}$

PQRS, Physician Quality Reporting Program; VBM, Value-Based Payment Modifier adjustments that are made under the PQRS and the EHR Incentive Program.

STEP 2 is to plan for VBM component by reviewing your QRUR.

LB Ok, can you explain the QRUR and how we find ours? RZ Most folks are not familiar with the QRUR, the Quality and Resource Use Reports. This report shows how your TIN, your Tax Identification Number, performed on quality and cost [Figure 7]. There is an annual QRUR that is available in the fall for the previous year's reporting period. For example, by fall 2017 you can get your QRUR for calendar year 2016. The way you access the QRUR is that one person from your TIN must register to attain the QRUR. Currently, you can get your QRUR for the year

Quality and Resource Use Reports (QRUR)

- Shows how you performed on quality and cost - QRUR is provided for each TIN (tax i.d. number)

- Annual QRUR available in the fall after the reporting period (fall 2017 for calendar year 2016)

- One person from your TIN must register to obtain your QRUR

- http://www.cms.gov/Medicare/Medicare-Fee-for-Service-Payment/ PhysicianFeedbackProgram/Obtain-2013-QRUR.html

FIGURE 7 Step 2: Review your QRUR

2014 and soon for 2015. Within the QRUR will be many, many pages of explanation.

What I'm going to focus on is the summary page, which you want to look at as soon as you get your QRUR to get a sense of how your practice is doing under the Quality and Cost Reporting. What you'll see in the summary page is the top line that will show your TIN, quality composite score, and there's a scale with the average range and then standard deviations from national mean. You want to be on the positive side, because that indicates that your quality is better than average [Figure 8]. The second line will have your TIN's cost composite score, and again it'll be a scale and it'll show you the average as well as the standard deviations from national mean. In this case, a negative score is better because you want to prove that cost of care under your TIN is less than average. Then both of those numbers are matriculated and you will see a scatter plot and the scatter plot is your TIN's performance with regard to average quality and average cost [Figure 9].

There are four quadrants and a shaded area of standard deviation and an average. Now if you're in the average range, you will not get any adjustment in this category towards your composite score. But there are other quadrants including high quality and low cost, high quality and high cost, low quality and high cost, and low quality and low cost. You want to be in the high quality and low 
cost because that's where the greatest reward is going to be.

In your report, underneath the scatter plot will be an explanation and it will talk about high-risk bonus adjustment and I'll give you an example and in that particular example it's not eligible [Figure 10]. What this describes is what your average beneficiary risk is for your TIN and a particular example that I'm referring to is the 77 th percentile of beneficiaries nationwide. Then what it explains is the Medicare determination for your TIN's eligibility for additional upward adjustment for serving high-risk beneficiary based on whether your TIN met [ indicated with checkmark] or did not meet [indicated with $\mathrm{X}$ ] the following criteria in 2014. In this particular sample report, the TIN's average beneficiary risk is at or above the 75 th percentile so they get a checkmark but their TIN did not have strong quality and cost performance so they got an X.

Although their TIN was able to avoid PQRS payment adjustments as a group, it was due to the fact that at least $50 \%$ of their eligible professionals met the criteria to avoid PQRS payment adjustment as individuals in 2016. Below that will be something called the TIN Value Modifier that I mentioned earlier [Figure 11]. What it does is that it calculates based on quality and cost what your additional adjustment from the value modifier will be. In this particular example it's $0 \%$ but it can range anywhere from a $-2 \%$ if you demonstrated low quality and high cost up to $+2 \%$ if in fact you demonstrated low cost and high quality.

STEP 3, focus on performance. I hope I've helped you understand that the way to improve your scores is to review the quality benchmarks and understand what is required for you in your practice to be able to have above-average performance. Then implement practice strategies and clinical workflows to help meet your chosen quality measures for PQRS and the quality and cost measures that are used under the value modifier program. With regard to EHR use, you want to be able to implement workflows to introduce patients to the patient portal but then also actually encourage them to use it.

\section{LB What about the cost measures? What is included and how can we impact this component?}

RZ Well, you want to establish processes to monitor hospitalizations and measure length of stay. You also may want to consider medical-home-type services to reduce hospi-

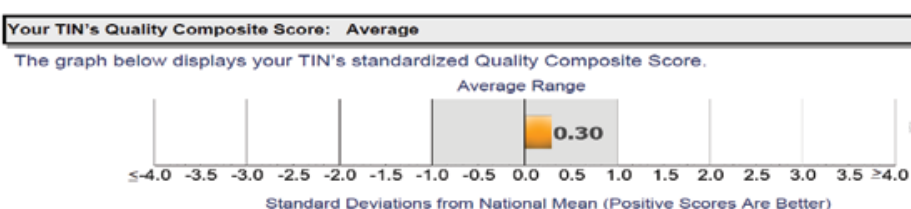

Your TIN's Cost Composite Score: Average

The graph below displays your TIN's standardized Cost Composite Score.

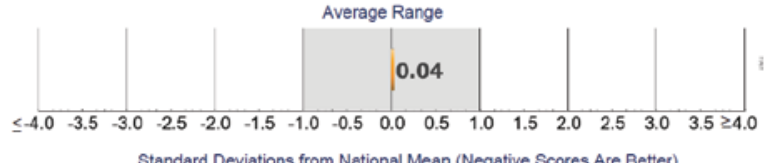

Standard Deviations from Netional Mean (Negative Scores Are Better)

FIGURE 8 What does your QRUR show?

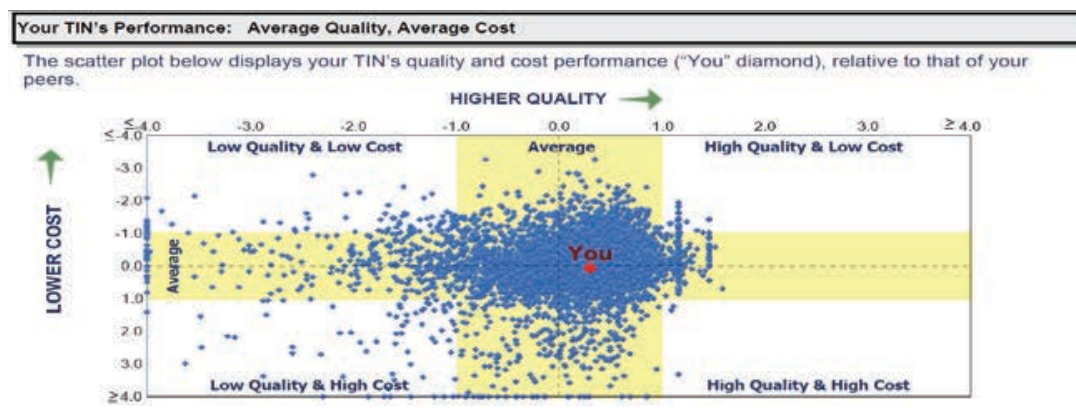

FIGURE 9 Your QRUR scatterplot

\section{High-Risk Bonus Adjustment: Not Eligible}

The average beneficiary risk for your TIN is at the 77 th percentile of beneficiaries nationwide.

Medicare determined your TIN's eligibility for an additional upward adjustment for serving high-risk beneficiaries based on whether your TIN met $(\checkmark)$ or did not meet $(x)$ the following criteria in 2014

Your TIN's average beneficiary's risk is at or above the 75th percentile of beneficiaries nationwide.

* Your TIN had strong quality and cost performance.

Your TIN met the criteria to avoid the PQRS payment adjustment as a group, or at least 50 percent of your TIN's eligible professionals met the criteria to avoid the PQRS payment adiustment as individuals in 2016 .

FIGURE 10 High-risk bonus adjustment

\begin{tabular}{|c|c|c|c|}
\hline \multicolumn{4}{|c|}{ Your TIN's Value Modifier: Neutral Adjustment } \\
\hline \multicolumn{4}{|c|}{$\begin{array}{l}\text { The highlighted payment adjustment will be applied to payments under the Medicare Physician Fee Schedule for } \\
\text { physicians billing under in your TIN in } 2016 \text {. }\end{array}$} \\
\hline & Low Quality & Average Quality & High Quality \\
\hline Low Cost & $+0.0 \%$ & $+1.0 \times \mathrm{AF}$ & $+2.0 \times \mathrm{AF}$ \\
\hline Average Cost & $-1.0 \%$ & $0.0 \%$ & $+1.0 \times \mathrm{AF}$ \\
\hline High Cost & $-2.0 \%$ & $-1.0 \%$ & $0.0 \%$ \\
\hline
\end{tabular}

FIGURE 11 The TIN's value modifier

talization. You may also want to look at how your providers are treating patients and determine whether or not in situations where there may be multisource drugs available that are generic, they could possibly be preferred over those that may be brand name.

In addition, you may also want to look at the practice's mechanism for end-of-life and palliative care and come to some agreement about how you're going to improve the end-of-life cost. 
STEP 4, ensure data accuracy. It is very important that you assure the accuracy of your group information and your data because you're going to be compared with groups that look just like you. For example, you want to check the National Provider Identifier [NPI] for each physician and practice and make sure the specialty is correct. In our practice, when we checked the NPI for one of our physicians some time ago it said they were an endocrinologist. Well, if they are being compared against endocrinologists they're going to be way off the scale because clearly they're giving chemotherapy and they would be much higher cost than an endocrinologist would be.

Also you want to look at the address, make sure that is correct and that the group affiliation is correct. You also want to go to something called Physician Compare, a CMS website, and review your own information. Within Physician Compare, it has not only contact information and addresses but also a list of the providers, and I have found in reviewing our own Physician Compare in the past that it was incorrect. In addition, there were providers who were being considered within my group who were no longer with our group.

STEP 5, recommends that you audit and educate your practice on proper use of the International Classification of Diseases, Revision 10, or ICD-10, coding. Practitioners need to realize that you need to code to the highest level of specificity because remember, when I talked about the QRUR summary page, part of the adjustment calculation is based on the risk of your beneficiary population. We're moving not only to a value over volume system, but they're also changing payments based on risk adjustments, so you need to be absolutely certain that your coders are coding all the comorbidities and other conditions as these will become increasingly important.

\section{How to survive MACRA}

LB So, what is essential to practice survival as we move to a MACRA-based payment system whether under MIPS or AAPM models?

RZ Well, three things. First, practice leadership. The leadership of your practice not only includes the president or the CEO of your practice, but also your chief financial officer, the folks who actually supervise the billers, your clinical managers, and your practicing administrators. All need to be on board, because as you move from value to volume, they will need to be functioning as a team to help optimize your reward and avoid penalty. Second, develop relationships with payers.

LB Why do practices need to develop awareness and good relationships with payers?

RZ As I mentioned, this is clearly a CMS-driven project. In the Advanced APM, however, to have qualified partici- pation, ultimately it will be based on the percentage of your payment revenue that goes through Advanced APM. As it turns out, it escalates over a period of years and it will not be covered solely by Medicare beneficiaries going through APMs, but also your commercial lives. You need to start talking with some of your payers now and asking them if they are interested or they have plans in participating in an Advanced APM in the future.

LB Can you comment on the third element essential for survival: the need for communication and training?

$\mathrm{RZ}$ This is a culture change for many practices as we move away from volume- and go toward value-based care and payments. There's a readiness, there's a philosophy, there's an ethos that must actually occur within the providers themselves and that includes not just the physicians but also the nurse practitioners and physician assistants and the entire staff.

LB What are some additional considerations that practitioners may want to make regarding the future?

RZ You need to consider what the impact of value-based payments is going to be on your physician compensation model. For example, if you have a model that is volume driven and this is actually paying you for value, how are you going to adjust your physician compensation as well as their activities and set up the teams necessary to carry out such a comprehensive practice change in order to earn the best payment rates?

Other considerations include your current contracts and your professional services agreements [PSAs] with hospitals and what they're requiring you to do. Finally, as I mentioned, commercial payer contracts also need to be reviewed. Another consideration is whether or not your current EHR can support the quality reporting and practice improvement. Do you have a patient portal? Do you have e-prescribing capability? Do you have the capability of accessing information through the health information exchange so both patients and providers can more easily and more readily get records about beneficiary care?

\section{Tools and 'how-to' programs}

LB Can you comment on what ASCO is providing as tools and programs to help practices understand MACRA?

RZ ASCO itself is approaching the MACRA transformation, which is both a care and payment transformation, in a three-pronged strategy.

First, a volunteer taskforce that includes the clinical practice committee, the government relations committee, and experienced ASCO staff is learning to understand MACRA and what's required. We also have the Quality Oncology Practice Initiative [QOPI] certification program that will continue to evolve and hopefully be part 
of the solution in terms of quality reporting for MACRA. Finally, under the volunteer taskforce work, is the work done on an APM strategy called Patient-Centered Oncology Payment [PCOP], which was released last year, May of 2015. The goal is for PCOP to become an Advanced APM for which many oncologists can qualify as most who read the MACRA legislation would prefer to participate in MACRA via an AAPM over the MIPS option. ASCO is also developing a number of practice tools, many of which will be on the ASCO website for members.

The second prong of the strategy regards education and resources, such as a survey that was recently released that looked at readiness assessment and webinars, which have occurred and will continue to occur. In addition, there will be a MACRA workshop at the ASCO headquarters in Alexandria, virgnia, in the fall of 2016. Finally, ASCO is going to have an oncology practice conference, the business of cancer care, which will be launched on March 2, 2017 in Orlando, Florida, the day before the Quality Symposia, It will provide updates from the final rules expected by the end of this year and networking discussions on MACRA for participants.

The third part of the strategy is to influence policy makers. ASCO has been filing extensive comments about MACRA and the components as well as meeting with CMS and policy makers, which includes not only the staff but also volunteers. Finally, ASCO has been conducting educational programs for the Congress members and staff as well as outreach and testimony.

LB Robin, that was really helpful and a tour de force to go through all of these components and break them down to help us understand the various options and implications under the new MACRA legislation. Really what we have to do now is the basic blocking and tackling as you've mentioned to understand where we are, what our practices are doing, and emphasize the need to keep participating in the current quality programs while understanding our QRUR which will impact the new, fourth metric of costs and value in the pending composite scores. I think this will be really very helpful to our oncology community. With the clinical affairs department at ASCO, people can access a growing amount of resources on the ASCO website. There's also an ASCO practice administrator's network and our PatientCentered Oncology Payment work to support these transitions. There's also a physician payment reform group looking at how practices might look at paying doctors differently under these models. Keep updated on the ASCO website and stay tuned for more support from the ASCO.

Thank you so much for talking to our journal and making this information more available for all of our colleagues throughout the country as we prepare for MACRA and moving from volume- to value-based care.

RZ My absolute pleasure. Thank you.

\section{ASCO urges members to 'report something' in 2017, despite CMS offer of flexibility}

In early September, CMS Acting Administrator Andy Slavitt announced that the agency would give physicians more options for participation in the quality payment programs in 2017 without risking negative adjustments so that practices of all sizes would have the opportunity to be successful.

The move was in response to appeals from the medical community that CMS revisit the original timeline for the implementation of MACRA.

The agency is reviewing comments on its proposed regulations, with a final rule expected in November.

Sybil Green, director of Coverage and Reimbursement in ASCO's Policy and Advocacy Department, said in a statement that, "consistent with guidance from [CMS, the society has] reminded members of their obligation to report and to start by reporting something in 2017."

"ASCO has invested in member readiness to ensure that practices are prepared to meet the requirements of $P Q R S$ and $M U$ reporting and participation in the VBM program in 2017, she noted.

Ms Green said at least one option under the more flexible timeline seems to allow practices to avoid penalties by reporting for part of the year and not be adversely affected. Another two options would allow practices to report more and over the full year, allowing providers to get positive payment adjustments.

"This flexibility is welcome, but we anticipate more details in the final rule and will be able to comment on the impact to members at that time," she commented.

ASCO continues to encourage CMS to test new APMs to allow physicians to take advantage of the fourth option - participation in an APM, which is one of only three exemptions from the MIPS reporting requirement, said $M s$ Green.

Currently, the CMS recognizes 5 Advanced Payment Models as "advanced," none of which are open to oncologists. The sixth model, the Oncology Care Model, is recognized.

"Fewer than 200 practices are participating in the OCM, which will not be an eligible APM until 2018, when the risk model adequately matches the requirements for an Advanced APM. Therefore, most oncologists will be subject to MIPS and relying on some flexibility in how they report so that they can be successful when MACRA is implemented," she said.

- Gregory Twachtman and Renee Matthews 